\title{
Teaching methods of history and geography and it influence for students in primary schools, vietnam
}

Nguyen Manh Huong ${ }^{1}$ Le Thi Thuy $\mathbf{A n}^{2}$

Dinh Tran Ngoc Huy ${ }^{3}$ Nguyen Thi Phuong Thanh ${ }^{4}$

Nhu Thi Phuong Lan

Chu Thi Mai Huong ${ }^{6}$ Mai Van $\mathrm{Nam}^{7}$

\section{Journal for Educators, Teachers and Trainers, Vol. 12 (1)}

\section{https://jett.labosfor.com/}

Date of reception: 12 October 2020

Date of revision: 11 January 2021

Date of acceptance: 10 April 2021

Nguyen Manh Huong, Le Thi Thuy An, Dinh Tran Ngoc Huy, Nguyen Thi Phuong Thanh, Nhu Thi Phuong Lan, Chu Thi Mai Huong, Mai Van Nam(2021). Impact and features of Chinese realism in painting with focus on tradition and modernity. Journal for Educators, Teachers and Trainers, Vol. 12(1). 173 - 178.

${ }^{1}$ Assoc. Prof. Senior lecturer, Faculty of History, Ha Noi National University of Education (No 136, Xuan Thuy St., Ha Noi, Vietnam)

${ }^{2}$ M.A Main lecturer, Department of Education, Tay Nguyen University, No 567, Le Duan St., Buon Ma Thuot City, Vietnam.

${ }^{3}$ MBA, Banking University HCMC, Ho Chi Minh city Vietnam - International University of Japan, Niigata, Japan; ${ }^{4} \mathrm{PhD}$, Main lecturer, Department of History, Ha Noi National University of Education (No 136, Xuan Thuy St., Ha Noi, Vietnam).

${ }^{5}$ M.A Main lecturer, Faculty of History, Ho Chi Minh City University of Education (No 280 An Duong Vuong St., Ho Chi Minh City, Viet Nam).

${ }^{6} \mathrm{PhD}$, Lecturer, Faculty of Social Sciences, Tay Bac University (Chu Van An St., Son La City, Vietnam); E-mail: ${ }^{7}$ PhD, Lecturer, Department of History, Thai Nguyen University of Education (No 20, Luong Ngoc Quyen St., Thai Nguyen, Vietnam). 


\title{
Teaching methods of history and geography and it influence for students in primary schools, vietnam
}

Nguyen Manh Huong ${ }^{*}$, Le Thi Thuy An ${ }^{2}$, Dinh Tran Ngoc Huy ${ }^{3}$, Nguyen Thi Phuong Thanh ${ }^{4}$, Nhu Thi Phuong Lan ${ }^{5}$, Chu Thi Mai Huong ${ }^{6}$, Mai Van Nam ${ }^{7}$

${ }^{1}$ Assoc. Prof. Senior lecturer, Faculty of History, Ha Noi National University of Education (No 136, Xuan Thuy St., Ha Noi, Vietnam)

${ }^{2}$ M.A Main lecturer, Department of Education, Tay Nguyen University, No 567, Le Duan St., Buon Ma Thuot City, Vietnam.

${ }^{3}$ MBA, Banking University HCMC, Ho Chi Minh city Vietnam - International University of Japan, Niigata, Japan; ${ }^{4} \mathrm{PhD}$, Main lecturer, Department of History, Ha Noi National University of Education (No 136, Xuan Thuy St., Ha Noi, Vietnam).

${ }^{5}$ M.A Main lecturer, Faculty of History, Ho Chi Minh City University of Education (No 280 An Duong Vuong St., Ho Chi Minh City, Viet Nam).

${ }^{6} \mathrm{PhD}$, Lecturer, Faculty of Social Sciences, Tay Bac University (Chu Van An St., Son La City, Vietnam); E-mail: ${ }^{7} \mathrm{PhD}$, Lecturer, Department of History, Thai Nguyen University of Education (No 20, Luong Ngoc Quyen St., Thai Nguyen, Vietnam).

*Corresponding Author

Email ID: nmhuongsphn@gmail.com, ltta@ttn.edu.vn,dtnhuy2010@gmail.com, phuongthanh2007@gmail.com, lanntp@hcmue.edu.vn, chumaihuong@utb.edu.vn,nammv@tnue.edu.vn

\begin{abstract}
ICT, IoTs (Internet of Things)and AI (artificial Intelligence) nowadays can have certain influence on teaching methods of history and geography for students in primary schools in emerging markets such as Vietnam. Through these methods of teaching, students and pupils in primary schools can have competent development. To achieve the results, authors use some research methods, including document analysis, pedagogical observation, qualitative analysis, synthesis and inductive methods, survey at primary schools in Dak Lak province. We see that teachers' skills such as psychological, pedagogy and computer skills will affect their students' thinking ability, creativity and IT skills, etc. Also, we emphasizes on story telling method for students from lecturers side.
\end{abstract}

Keywords: Information Technology, Internet of Things, AI, teaching History and Geography, students' competency development, Vietnam

\section{INTRODUCTION}

Using ICT, IotS and AI and applying them in history and geography subjects teaching in primary schools will contribute to develop ICT ability for students. This is $1^{\text {st }}$ teaching method we want to present.

Teaching history and geography via pictures and visual images are also a good teaching method.

Taking students or pupils to historical sites or historical and cultural places is the $3^{\text {rd }}$ method we would like to explain in this paper.

These methods need to be used widely and creatively in various primary schools in the specific condition of Vietnam, a developing country in Asia since the Vietnam war after 1975 to now.

For pupils in primary schools, it is much depending on teachers' skills such as pedagogy and psychological and computer skills. Then they can help students or pupils to develop IT skills, their imaginary and creativity.

This paper organized with introduction, literature review, methods, main results, discussion and conclusion.

\section{LITERATURE REVIEW}

First of all, Dilek (2010) stated that when they drew pictures, pupils will describe more on scenes of history and events of history with support of resources.

Authors us a qualitative approach to study. Students' problem solving ability in history can be supported and developed with this way of teaching method, as well as their visual thinking ability

Then, Apostostolido (2012) specified teachers need to pay attention to teaching history subjects with sectors involving life and culture, etc. in a constructing way that relate to students (Barton, 2009 and Von Borries, 2009). Then we need to take care of the environment of teaching in which students by their own can develop consciousness of history (Erdmann, 2008). 
Beside, Skjaevelan (2017) pointed that the roles of teachers are vital in teaching history for children and pupils, as they can apply a wide rage of teaching methods and they are those who make assessment of students' ability to obtain history and geography subjects.

According to the General Education program 2018, informatics capacity is one of the competencies that students need to achieve when completing high school programs. Informatics capacity includes 05 elements: (1) Use and manage information technology and communication media; (2) Appropriate behavior in a digital environment; (3) Solve the problem with the assistance of information and communication technology; (4) Apply information and communication technology in learning and self-study; (5) Collaboration in a digital environment. (Huong, N.M et al , 2021).

\section{METHODOLOGY}

This study mainly uses qualitative methods, with synthesis, analytical and inductive methods, combined with historical and dialectical materialism analysis methods.

Authors also use some research methods, including document analysis, pedagogical observation, qualitative analysis, synthesis and inductive methods, survey at primary schools in Dak Lak province.

\section{MAIN RESULTS}

Teaching method through visual pictures and images: Watching documentary films in schools or in cinemas or theaters can be a good way for developing students' thinking ability and attracting more students' attention. Many teachers can think of using laptops, movies, presentations, pictures, etc. To visualize historical and geographical topics and attract more attention from pupils. Moreover, we can teach students via providing them with historical stories to read in our outside classroom or in libraries.

For instance, nowadays students can buy and read historical tries in pictures to know more about the world around:
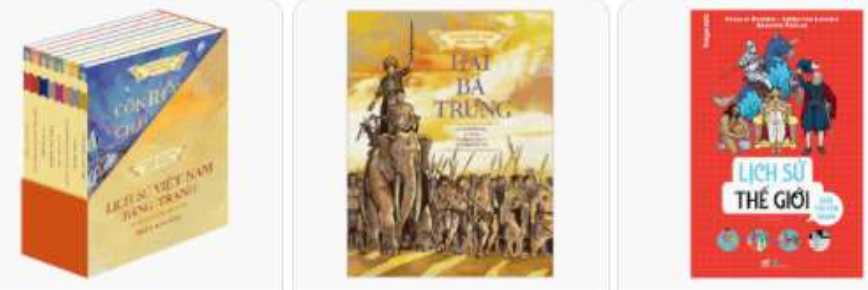

Fig.1: Understand world historical stories

(source: Vietnam bookstores)

\section{Developing students' learning ability with IT, AI and IoTs}

First, applying IoTs (Internet of Things) in teaching history and geography subjects in primary schools can be explore through:

Roles of IoTs can expand a lot of knowledge for students in primary schools through connection between computer and internet. IoTs can deal with Big Data and provide true pictures and images for developing students' learning ability.

IoTs will help us to connect many libraries and schools in a country and in the world together to deliver a better historical or geographical picture.

A interesting program delivered with IT applications and images and colorful pictures and interface will enable and encourage students and pupils in listening and watching history subjects.

Second, applying AI (Artificial Intelligence) in teaching history and geography subjects in primary schools can be explore through :

We can apply concepts of AI and machine learning (ML) into teaching history and geography, and other subjects at schools.

Chatbot, Robot and AI applications of face and hand gestures of students, and help teachers in deliver subjects contents to learners in classroom environment or from far distance. E-learning is another way to deliver lecture notes to students.

Next, we analyze a survey on IT skills for pupils in primary schools in history and geography

Huong, N.M et al (2021) has done a survey with 55 teachers in primary schools in Daklak province Vietnam.

In this survey, Huong, N.M et al (2021) has said that IT using is very vital to develop students' computer skills, beside, presentation and smart tivis.

* Which of the following equipment is available in the classroom / classroom teacher / teacher is teaching (select all available equipment)?

Chart 1 


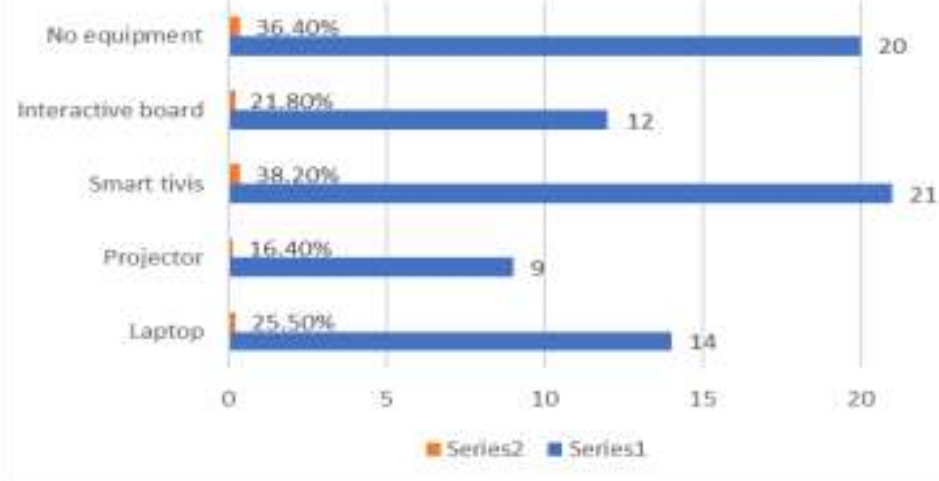

Fig.2: Teaching facilities and equipment in each Classroom

* What difficulties / barriers do you meet in the process of developing computer skills / competencies for students through History and Geography? (Can choose from many options)

Table 1: Investigation results of teachers wen they develop IT skills for students in history and geography subjects

\begin{tabular}{|c|c|c|c|c|c|c|c|c|c|c|c|}
\hline Order & Obstacles & \multicolumn{10}{|l|}{ Level } \\
\hline 1 & $\begin{array}{l}\text { School vision and strategy with IT } \\
\text { applying }\end{array}$ & 13 & 23.6 & 3 & 5.5 & 28 & 50.9 & 9 & 16.4 & 2 & 3.6 \\
\hline 2 & School technical support & 12 & 21.8 & 8 & 14.5 & 24 & 43.6 & 7 & 12.7 & 4 & 7.3 \\
\hline 3 & School, Classroom infrastructure & 13 & 23.6 & 5 & 9.1 & 20 & 36.4 & 12 & 21.8 & 5 & 9.1 \\
\hline 4 & IT training courses & 8 & 14.5 & 7 & 12.7 & 3.2 & 58.2 & 4 & 7.3 & 4 & 7.3 \\
\hline 7 & $\begin{array}{l}\text { Family conditions for students to } \\
\text { use IT }\end{array}$ & 6 & 10.9 & 9 & 16.4 & 16 & 29.1 & 20 & 36.4 & 4 & 7.3 \\
\hline 8 & Students IT skills & 4 & 7.3 & 8 & 14.5 & 28 & 50.9 & 10 & 18.2 & 5 & 9.1 \\
\hline 9 & Self -learning of students & 4 & 7.3 & 7 & 12.7 & 29 & 52.7 & 11 & 20 & 4 & 7.3 \\
\hline
\end{tabular}

(source : investigation data)

Through survey data and in-depth interviews, teachers believe that the biggest difficulties come from the physical conditions of the School, Class and the condition of parents. Therefore, many primary schools, although learning information technology, mainly study theory. Parents' circumstances are very difficult, so there is no support for schools as well as students in computer practice. Another factor stemming from many students in many schools is ethnic minority students. At primary level, students' computer skills are limited beside language barriers.

Taking students or pupils to historical sites or historical and cultural places is the $3^{\text {rd }}$ method we would like to explain in this paper.

In Vietnam, as well as in other developing countries, there are many historical sites and cultural places where we can take students to visit, take pictures, listen to tour guides to tell about historical stories, in more than 63 provinces and cities in Vietnam.

This is called outside or outdoor activities for our students.

Huong, N.M et al (2021) mentioned that Teachers need to regularly discuss with parents, especially in parent conferences, especially parent conferences at the beginning of the year, in groups such as Zalo, Facebook ... for general orientation and help. Together the school deployed to parents on socialization of education. Helping parents to be aware of the importance of IT in today's era and to coordinate with teachers and schools in equipping students' computing platforms, skills and capacities.

\section{DISCUSSION}

Huong, N.M (2021) mentioned that At the same time with special students of primary school age, the teacher is always a role model, "idol" of students. Teachers need to be aware of the importance of IT and have guidance for students to build motivation and learning style with IT support. Teachers' guidance does not stop at reminding and guiding students to use IT properly, avoiding dangers in the process of using the Internet. In teaching History and Geography, with searching information, video materials, and pictures, teachers can give specific instructions, providing official websites for students. 
For example, teachers can include and guise their students t real historical stories with pictures:

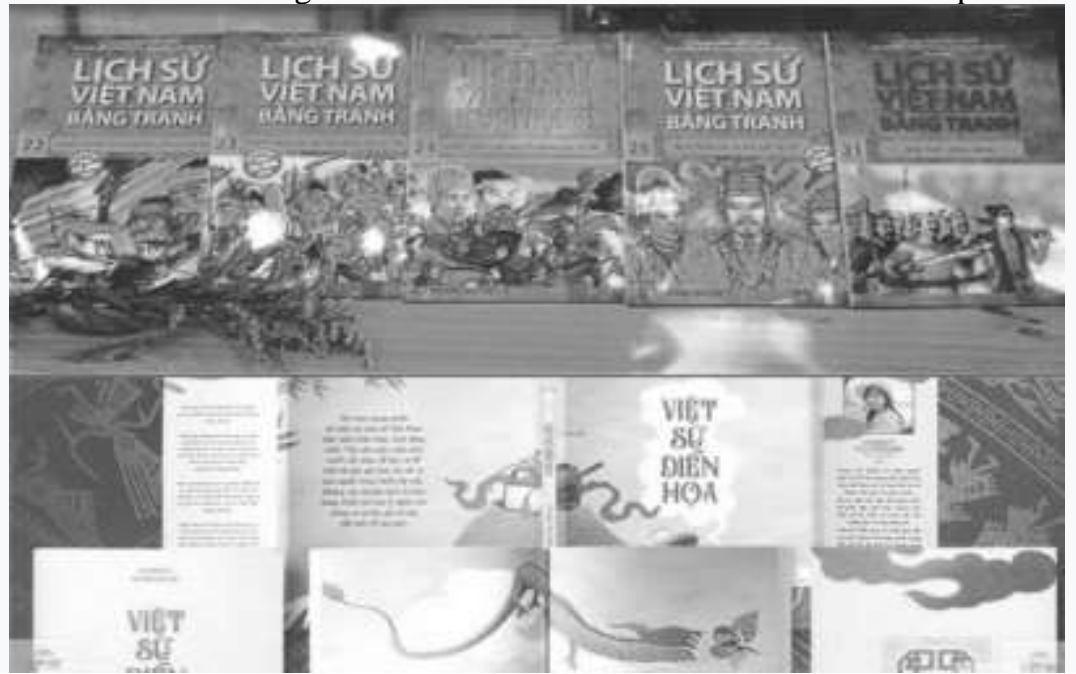

Fig.3: Reading historical stories with pictures

(source: suckhoedoisong.vn)

\section{CONCLUSION}

Vietnam education is on the way to integrate with global education, therefore teachers need not only to improve teaching skills, teaching methods including psychological and pedagogy methods, but also need to develop ICT skills to transfer knowledge and values of history and geography subjects to their students in primary schools, and moreover in high schools and colleges or universities later.

History and geography subjects teaching with pictures also bring historical stories to students read and reduce boredness of students or pupils in classroom environment.

Applying IoTs into teaching will help to develop teachers and students, in a modern education way, to deliver good knowledge via e-books.

For those who love teaching in primary schools and high schools and further, applying IoTs and AI in history and geography subjects are worth to consider and invest into it.

\section{LIMITATION OF RESEARCH}

We need to expand teaching methods for other subjects such as foreign languages, IT, Linguistics, literature, mathematics, physics, etc. We still limit the survey in Daklak province so we can expand surveys into other provinces in Vietnam or countries.

Acknowledgement: Thank you editors, friends to assist this publishing.

\section{REFERENCES}

1. Felipe Oyarzo Pineida (2011), Competencies for the 21st century: integrating ICT to life, school and economical development, Procedia-Social and Behavioral Sciences, 28, pp.54-57.

2. Areti Chalkiadaki (2018), A systematic literature review of 21st century skills and competencies in primary education, International Journal of Instruction, số 11(3), pp. 1-16.

3. Apostostolidou, E (2012), Teaching and discussing historical significance with 15 year old students in Greece, International Journal of Historical Learning, Teaching and Research, Vol. 11.1, 2012, pp 7-23

4. Dilek, G. (2010). Visual thinking in teaching history: reading the visual thinking skills of 12 yearold pupils in Istanbul, International Journal of Primary, Elementary and Early Years Education, 38(3). https:/ / doi.org/10.1080/03004279.2010.497276

5. Felipe Oyarzo Pineida (2011), Competencies for the 21st century: integrating ICT to life, school and economical development, Procedia-Social and Behavioral Sciences, 28, pp.54-57.

6. UNESCO (2011), UNESCO's ICT Competency Standards for Teachers, UNESCO, France.

7. Joke Voogt, Natalie Pareja Roblin (2012), A comparative analysis of international frameworks for 21st century competences: Implications for national curriculum policies, Journal of curriculum studies, 44(3), pp. 299-321. 
8. Le Thi Thanh Huong, Do Thu Huong, Dinh Tran Ngoc Huy, Nguyen Thu Thuy. (2021), Education for students to enhance research skills and meet demand from workplace - case in Vietnam, Elementary Education Online, 20(4): 606-611. Doi: 10.17051/ilkonline.2021.04.66

9. Nguyen Manh Huong (2011), Improving teaching quality of History at high schools with the support of information technology, Doctoral thesis in Education, National Library, H, 2011.

10. Huong, N.M, An, L.T.T.T, Thanh, N.T.P, Lan, N.T.P, Huong, C.T.M, \& Nam, M.V. (2021). Formulation and development of it ability for students in primary school, vietnam through history and geography subjects, Elementary education online, 20(4).

11. Ministry of Education and Training (2006), Decision No. 16/2006 / QD-BGDĐT dated 05/05/2006 Promulgating General Education Program, Vietnam.

12. Ministry of Education and Training (2018), General Education Program Master Program, Hanoi, Vietnam.

13. Koen Aesaert, Daniël Van Nijlen, Ruben Vanderlinde, Jo Tondeur, Ines Devlieger, Johan van Braak (2015), The contribution of pupil, classroom and school level characteristics to primary school pupils' ICT competences: A performance-based approach, Computers \& Education, 87, pp. 55-69.

14. Phan Ngoc Lien (2009) (Editor). Teaching Methodology History (Vol.1, 2), Pedagogical University Publishing House, Hanoi, Vietnam.

15. Skjaeveland, Y. (2017). Learning history in early childhood: Teaching methods and children's understanding, Contemporary issues in early childhood, 1. https://doi.org/10.1177/1463949117692262

16. Thuy Dung Thi Vu, Le Thi Thanh Huong, Dinh Tran Ngoc Huy, Le Ngoc Nuong, Ngo Thi Huyen Trang, Nguyen Ngoc Thach. (2021). Human Education and Educational Issues for Society and Economy - Case In Emerging Markets Including Vietnam, Elementary Education Online, 20(2): 216221. Doi: 10.17051/ilkonline.2021.02.27

17. Thuy Dung Vu Thi, Tran Nguyet Minh Thu, Dinh Tran Ngoc Huy, Nguyen Thu Thuy. (2021). Effects of western culture and ho chi minh ideology on Vietnam education, Elementary education online, 20(4): 612-616. Doi: 10.17051/ilkonline.2021.04.67

18. Tran Nguyet Minh Thu, Thuy Dung Vu Thi, Nguyen Thu Thuy, Dinh Tran Ngoc Huy. (2021). Confucianism Theories and Its Influence on Vietnam Society, Elementary Education Online, 20(4):1434-1437.

19. Tran Nguyet Minh Thu, Dinh Tran Ngoc Huy, Thuy Dung Vu Thi, Le Ngoc Nuong. (2021). Effects of western and chinese culture and ideology on vietnam society, Elementary Education Online, 20(4): 1438-1441. Doi: 10.17051/ilkonline.2021.04.163

20. https://dinhtranngochuy.com/category/blog/ (date access: 16/5/2021). 